\title{
ANALISIS STATUS ANEMIA IBU HAMIL \\ TERHADAP KEJADIAN BERAT BADAN LAHIR RENDAH (BBLR) \\ (Studi Data Sekunder dari Register Kohort Ibu dan Buku KIA di Wilayah Kerja \\ UPTD Puskesmas Manggari Kabupaten Kuningan Tahun 2019)
}

\section{OLEH :}

\author{
Usep Rusependhi ${ }^{1}$, Diah Mulyawati Utari ${ }^{2}$ \\ Program Studi Ilmu Kesehatan Masyarakat Departemen Gizi Kesmas UI
}

Email: usep1974kuningan@gmail.com

\begin{abstract}
A. ABSTRAK
Berat badan lahir rendah (BBLR) yaitu bayi dengan berat badan saat lahir kurang dari 2.500 gram. Bayi yang lahir dengan BBLR memiliki risiko meninggal pada awal kelahiran, tumbuh dan berkembang lebih lambat dibandingkan dengan bayi yang lahir dengan berat badan normal, serta berisiko terjadinya penyakit hipertensi, jantung dan diabetes di kemudian hari (WHO, 2014). Prevalensi BBLR paling tinggi di Kabupaten Kuningan tahun 2018 berada di wilayah kerja UPTD Puskesmas Manggari yaitu sebesar 11,8\% dengan prevalensi ibu hamil anemia sebesar 33,8\%. Salah satu faktor penyebab BBLR adalah anemia (kadar $\mathrm{Hb}<11,0 \mathrm{gr} / \mathrm{dl}$ ) yang dialami oleh ibu hamil (WHO, 2014). Tujuan penelitian ini adalah untuk mengetahui hubungan antara anemia ibu hamil dengan kejadian BBLR menggunakan desain penelitian case control data sekunder dari register kohort ibu dan buku KIA. Total sampel sebanyak 87 bayi, terdiri dari 29 kasus dan 58 kontrol yang memenuhi kriteria inklusi dan eksklusi. Analisis bivariat menggunakan uji Chi Square, diperoleh nilai $p=0,038$ menunjukkan adanya hubungan yang signifikan antara anemia ibu hamil dengan kejadian BBLR, dan diperoleh $O R=3,327$ (95\% CI: 1,184-9,351), yang berarti bahwa ibu hamil yang anemia beresiko 3,327 kali lebih tinggi untuk melahirkan BBLR dibandingkan dengan ibu hamil yang tidak anemia. Kesimpulan penelitian ini ada hubungan antara anemia ibu hamil dengan kejadian BBLR. Hal ini didukung oleh hasil penelitian Mohandas Nair, dkk, bahwa ibu hamil dengan kadar $H b<10$ gr/dl (anemia) memiliki risiko 4,3 kali lebih tinggi untuk melahirkan BBLR dibandingkan dengan ibu hamil yang tidak anemia. Selain itu, hasil systematic review study yang dilakukan oleh Bunyarit Sukrat, dkk diperoleh bahwa ibu hamil pada trimester 3 dengan kadar $\mathrm{Hb}<11 \mathrm{gr} / \mathrm{dl}$ berisiko 1,30 kali lebih tinggi untuk melahirkan BBLR. Begitu pula, hasil penelitian Mutiara Fatinah Endah diperoleh bahwa anemia pada ibu hamil Trimester III berhubungan dengan kejadian BBLR $(p=0,017$ OR=1,7). Penelitian lain oleh Rahmati, Shoboo et al berupa tinjauan sistematis literatur dan metode PRISMA menunjukkan bahwa hubungan anemia ibu hamil dan BBLR pada trimester pertama kehamilan adalah signifikan $(R R=1,26)$. Dari hasil penelitian ini, peneliti menyarankan supaya selama kehamilan, ibu hamil dapat mempertahankan kadar $\mathrm{Hb} \geq 11,0 \mathrm{gr} / \mathrm{dl}$ melalui konsumsi makanan sumber zat besi atau suplementasi tablet tambah darah (Fe) dan disarankan bagi tenaga kesehatan, supaya lebih meningkatkan kembali kegiatan penyuluhan tentang anemia dan pengawasan minum tablet Fe bagi ibu hamil untuk mencegah terjadinya kasus BBLR.
\end{abstract}

Kata kunci: Anemia ibu hamil, BBLR 


\section{B. LATAR BELAKANG}

Berat badan lahir rendah (BBLR) yaitu bayi dengan berat badan saat lahir kurang dari 2.500 gram (WHO, 2014), sedangkan menurut Kemenkes (2014), BBLR adalah bayi yang lahir dengan berat badan kurang dari 2.500 gram yang ditimbang pada saat lahir sampai dengan 24 jam pertama setelah lahir.

Bayi yang lahir dengan BBLR memiliki risiko meninggal pada awal kelahiran, tumbuh dan berkembang lebih lambat dibandingkan dengan bayi yang lahir dengan berat badan normal, serta berisiko tinggi untuk terjadinya penyakit hipertensi, jantung dan diabetes setelah mencapai usia 40 tahun. Menurut Moehji (1988), bayi dengan BBLR cenderung lebih mudah menderita berbagai penyakit infeksi, dan sering mengalami komplikasi yang berakhir dengan kematian yang disebabkan oleh keadaan organ-organ tubuh yang belum sempurna kematangannya.

Survei WHO pada tahun 2012 menyebutkan bahwa $15-20 \%$ bayi di dunia lahir dengan berat badan lahir rendah. Di Indonesia, berdasarkan hasil survei Riset Kesehatan Dasar (Riskesdas) tahun 2010-2018, prevalensi BBLR cenderung menurun yaitu dari $11,1 \%$ pada Riskesdas tahun 2010, turun menjadi $10,2 \%$ pada Riskesdas tahun 2013, dan selanjutnya turun lagi menjadi $6,2 \%$ pada Riskesdas tahun 2018. Namun meskipun ada penurunan kasus, BBLR masih merupakan masalah kesehatan yang utama dan harus segera diatasi, karena dampak yang ditimbulkannya terhadap kelangsungan sumber daya manusia (SDM) di masa yang akan datang.

Prevalensi BBLR di Provinsi Jawa Barat tahun 2016 sebesar 2,2\%, dimana Kabupaten Kuningan merupakan kabupaten dengan prevalensi BBLR yang cukup tinggi yaitu sebesar 5,7\%. Berdasarkan data profil Dinas Kesehatan Kabupaten Kuningan tahun 2018, prevalensi BBLR Kabupaten Kuningan mencapai $5,2 \%$, dengan prevalensi BBLR yang paling tinggi sebesar $11,8 \%$ berada di wilayah kerja UPTD Puskesmas Manggari. Selain BBLR, prevalensi ibu hamil anemia tahun 2018 di UPTD Puskesmas Manggari juga cukup tinggi yaitu sebesar 33,8 \% (peringkat ke-4 tertinggi dari 37 Puskesmas yang ada di Kabupaten Kuningan).

Berdasarkan beberapa literatur dan penelitian, BBLR dapat disebabkan oleh berbagai faktor diantaranya yaitu faktor kehamilan (meliputi riwayat anemia ibu, perdarahan antepartum, pemeriksaan ANC, hamil ganda, pre-eklamsia/eklamsia, ketuban pecah, dan penyakit masa kehamilan), faktor ibu (meliputi status KEK, status IMT, usia ibu, paritas, jarak kehamilan, paparan asap rokok, pekerjaan dan pendidikan ibu), dan faktor janin (meliputi cacat bawaan dan infeksi dalam rahim) (Maryanti (2011), Manuaba (2010), dan Prawirohardjo (2010). Dari berbagai teori dan literatur tersebut, maka dibuatkan kerangka teori yang merupakan kesimpulan dari tinjauan kepustakaan yang dibuat sebagai dasar untuk membuat kerangka konsep (Notoatmodjo, 2010)

Menurut WHO (2014) anemia pada masa kehamilan berdampak pada peningkatan angka mortalitas dan morbiditas pada ibu dan bayi serta berisiko terjadinya keguguran, lahir mati, prematur, dan berat badan lahir rendah (BBLR). Kekurangan zat gizi mikro yang mengakibatkan anemia (kadar $\mathrm{Hb}<11,0 \mathrm{gr} / \mathrm{dl}$ ), dapat mempengaruhi berat lahir bayi, sebab berhubungan dengan hambatan pertumbuhan janin akibat kurangnya pasokan oksigen menuju janin. Berdasarkan data terakhir dari the world bank data, prevalensi anemia ibu hamil di dunia pada tahun 2012-2016 mengalami peningkatan yaitu dari $39,4 \%$ menjadi $40,1 \%$. Begitu juga di Indonesia, prevalensi anemia ibu hamil terus mengalami kenaikan menjadi $42 \%$ pada tahun 2016. Hasil Riset Kesehatan Dasar (Riskesdas) tahun 2018 menunjukkan adanya peningkatan prevalensi anemia ibu hamil dari $37,1 \%$ pada Riskesdas tahun 2013, meningkat menjadi 48,9\% pada Riskesdas tahun 2018 (Kemenkes, 2018). Berdasarkan profil Dinas Kesehatan Provinsi Jawa Barat tahun 2016, besarnya angka kejadian anemia ibu hamil pada trimester I sebesar 20\%, trimester II sebesar 70\%, dan trimester III sebesar 70\% (Dinkes Prov. Jabar, 2016).

Tujuan penelitian ini untuk mengetahui hubungan antara anemia ibu hamil dengan kejadian berat badan lahir rendah. Manfaat penelitian ini adalah dalam rangka ikut andil untuk meningkatkan derajat kesehatan 
masyarakat, khususnya terkait kesehatan ibu hamil dan kejadian kasus berat badan lahir rendah (BBLR).

\section{METODOLOGI PENELITIAN}

Penelitian ini menggunakan jenis penelitian kuantitatif dengan desain kasus kontrol. Populasi dalam penelitian ini adalah seluruh bayi yang lahir pada bulan Januari sampai dengan Desember tahun 2019 dan berdomisili di wilayah kerja UPTD Puskesmas Manggari Kabupaten Kuningan. Total sampel dalam penelitian ini sebanyak 87 bayi yang terdiri dari 29 kelompok kasus (BBLR) dan 58 kelompok kontrol (BBLR) yang dibatasi oleh kriteria inklusi dan eksklusi. Penentuan jumlah minimal sampel berdasarkan hitungan menggunakan Size Determination in Health Studies (Lameshow S et al, 1990).

Jenis data dalam penelitian ini adalah data sekunder dari register kohort ibu dan buku KIA yang dibagi menjadi data BBLR sebagai variabel dependen dan data status anemia ibu hamil (Kadar Hemoglobin) sebagai variabel independen.

Teknik pengumpulan data yaitu semua bayi yang terdaftar di register kohort ibu hamil di wilayah kerja UPTD Puskesmas Manggari, diambil sesuai hasil perhitungan menggunakan rumus dari Lemeshow $\mathrm{S}$ et al (1990) yaitu rumus sampel minimal untuk kasus kontrol dua arah tidak berpadanan (Sample Size Determination in Health Studies) yaitu sebanyak 29 bayi BBLR (BB lahir < 2.500 gram) dan sebanyak 58 bayi dengan status kelahiran berat badan normal (BB lahir $\geq 2.500$ gram) sesuai kriteria inklusi dan eksklusi.

Kriteria inklusi, meliputi ibu yang memiliki bayi lahir hidup, anak terakhir, dan mempunyai data lengkap pada register kohort ibu dan buku KIA berupa variabel: berat badan bayi saat lahir, dan hasil pengukuran kadar $\mathrm{Hb}$. Kriteria eksklusi, meliputi: ibu yang mengalami perdarahan antepartum, hamil ganda/ anak kembar, pre-eklamsia/Eklamsia, ketuban pecah, penyakit masa kehamilan seperti DM saat hamil, hipertensi saat hamil, hamil kurang bulan $(<37$ minggu), janin cacat bawaan, dan infeksi dalam rahim.

Pengolahan data yang telah dikumpulkan dilakukan dengan cara manual dan menggunakan komputer meliputi 4 tahap yaitu editing, coding, dan processing menggunakan komputer (SPSS Versi 23). Kemudian dilakukan Analisis data menggunakan uji Chi Square berupa analisis univariat dan analisis bivariat antara anemia ibu hamil dengan kejadian BBLR.

\section{HASIL PENELITIAN}

\section{Analisis Univariat}

Hasil analisis univariat menampilkan gambaran sebaran karakteristik responden yang menjadi sampel dalam penelitian ini. Sampel dalam penelitian ini dikelompokkan kedalam kejadian berat badan lahir (BBLR dan BBLN) sebagai variabel dependen dan status anemia ibu hamil (anemia dan tidak anemia) sebagai variabel independen, dengan sebaran seperti terlihat pada tabel 5.1 dan tabel 5.2 sebagai berikut:

Tabel 5.1 Distribusi Frekuensi berdasarkan Kejadian BBLR di Wilayah Kerja UPTD Puskesmas Manggari Kabupaten Kuningan Tahun 2019

\begin{tabular}{|c|c|c|c|}
\hline No & Berat Bayi Lahir & $\begin{array}{c}\text { Jumlah } \\
(\mathrm{n})\end{array}$ & $\begin{array}{c}\text { Persentasi } \\
(\%)\end{array}$ \\
\hline 1 & $\begin{array}{c}\text { BBLR (BB }<2.500 \\
\text { gram })\end{array}$ & 29 & 33,3 \\
\hline 2 & $\begin{array}{c}\text { BBLN (BB } \geq 2.500 \\
\text { gram })\end{array}$ & 58 & 66,7 \\
\hline & Total & 87 & 100,0 \\
\hline
\end{tabular}

Berdasarkan tabel 5.1 dapat diketahui bahwa dari total sampel 87 ibu yang melahirkan bayi hidup pada tahun 2019, sebanyak 29 $(33,3 \%)$ ibu melahirkan bayi dengan berat badan lahir rendah (BBLR), sedangkan sisanya yaitu sebanyak $58(66,7 \%)$ melahirkan dengan berat badan normal. 
Tabel 5.2 Distribusi Frekuensi berdasarkan Status Anemia Ibu Hamil di Wilayah Kerja UPTD Puskesmas Manggarai Kabupaten Kuningan Tahun 2019

\begin{tabular}{|c|c|c|c|}
\hline No & Status Anemia Ibu Hamil & $\begin{array}{c}\text { Jumlah } \\
(\mathrm{n})\end{array}$ & $\begin{array}{c}\text { Persentasi } \\
(\%)\end{array}$ \\
\hline 1 & Anemia $(\mathrm{Hb}<11 \mathrm{gr} / \mathrm{dl})$ & 20 & 23,0 \\
\hline 2 & Tdk anemi $(\mathrm{Hb} \geq 11 \mathrm{gr} / \mathrm{dl})$ & 67 & 77,0 \\
\hline & Total & 87 & 100,0 \\
\hline
\end{tabular}

Berdasarkan tabel 5.2 dapat diketahui bahwa dari total sampel $87 \mathrm{ibu}$ hamil pada tahun 2019, sebanyak $20(23,0 \%)$ mengalami anemia, sedangkan sisanya yaitu sebanyak 67 $(77,0 \%)$ memiliki kadar Haemoglobin ( $\mathrm{Hb})$ normal.

\section{Analisis Bivariat}

Analisis bivariat bertujuan untuk mengetahui hubungan antara variabel independen dan variabel dependen dengan tanpa mempertimbangkan faktor-faktor lainnya yang mempengaruhi variabel dependen, seperti dapat terlihat pada tabel 5.3 berikut.

\section{Tabel 5.4 Hubungan antara Status Anemia Ibu Hamil dengan BBLR di Wilayah Kerja UPTD Puskesmas Manggarai Kabupaten Kuningan Tahun 2019}

\begin{tabular}{|c|c|c|c|c|c|c|c|}
\hline \multirow[t]{3}{*}{ Status Anemia Ibu Hamil } & \multicolumn{4}{|c|}{ Berat Badan Lahir } & \multirow[t]{3}{*}{ Nilai $\mathbf{P}$} & \multirow[t]{3}{*}{ OR } & \multirow[t]{3}{*}{$95 \% \mathrm{CI}$} \\
\hline & \multicolumn{2}{|c|}{ BBLR } & \multicolumn{2}{|c|}{ BBLN } & & & \\
\hline & $\mathbf{N}$ & $\%$ & $\mathbf{N}$ & $\%$ & & & \\
\hline Anemia $(\mathrm{Hb}<11 \mathrm{gr} / \mathrm{dl})$ & 11 & 55,0 & 9 & 45,0 & 0,038 & 3,327 & $1,184-9,351$ \\
\hline Normal $(\mathrm{Hb} \geq 11 \mathrm{gr} / \mathrm{dl})$ & 18 & 26,9 & 49 & 73,1 & & & \\
\hline
\end{tabular}

Berdasarkan tabel 5.4 dapat diketahui bahwa dari mereka yang mengalami kasus BBLR, ada sebanyak $11(55,0 \%)$ berasal dari ibu hamil yang mengalami anemia, sedangkan pada kelompok yang tidak BBLR ada sebanyak $9(45,0 \%)$ berasal dari ibu hamil yang mengalami anemia.

Hasil uji statistik menggunakan Chi Square, diperoleh nilai $\mathrm{p}=0,038$ yang berarti bahwa ada hubungan yang signifikan antara status anemia ibu hamil dengan kejadian BBLR dengan nilai $\mathrm{OR}=3,327$ (95\% CI: 1,184-9,351), yang artinya bahwa ibu hamil yang mengalami anemia mempunyai risiko sebesar 3,327 kali lebih tinggi dari ibu hamil yang tidak anemia untuk melahirkan BBLR 


\section{E. PEMBAHASAN}

Berdasarkan hasil analisis univariat diperoleh bahwa sebaran sampel dalam penelitian ini yaitu dari total 87 sampel yang diteliti, sebanyak $33,3 \%$ bayi lahir dengan BBLR dan $23,0 \%$ ibu hamil mengalami anemia $(\mathrm{Hb}<11 \mathrm{gr} / \mathrm{dl})$. Hal ini menandakan bahwa BBLR dan anemia masih merupakan masalah kesehatan ibu dan anak yang utama dan harus segera diantisipasi serta dilakukan pencegahannya melalui berbagai informasi publik dan penyuluhan terhadap WUS.

Berat badan lahir rendah (BBLR) didefinisikan oleh organisasi kesehatan dunia World Health Organization (WHO) yaitu berat badan saat lahir kurang dari 2.500 gram (WHO, 2014), sedangkan menurut Kemenkes RI (2014), berat badan lahir rendah (BBLR) adalah bayi yang lahir dengan berat badan kurang dari 2.500 gram yang ditimbang pada saat lahir sampai dengan 24 jam pertama setelah lahir. Menurut Saifuddin et al (2001) bayi berat lahir rendah (BBLR) adalah bayi dengan berat badan lahirnya kurang dari 2.500gram (sampai dengan 2.499 gram).

Bayi yang lahir dengan BBLR memiliki risiko meninggal pada awal kelahiran, tumbuh dan berkembang lebih lambat dibandingkan dengan bayi yang lahir dengan berat badan normal, serta setelah mencapai usia 40 tahun berisiko tinggi untuk terjadinya penyakit hipertensi, jantung dan diabetes. Berdasarkan pengamatan epidemiologis dapat diprediksi bahwa bayi dengan berat badan $<$ 2.500 gram

(BBLR) mempunyai kemungkinan risiko meninggal 20 kali dibandingkan dengan bayi yang dilahirkan dengan berat badan $\geq 2.500$ gram (BBLR), dan berkontribusi pada keadaan kesehatan yang buruk (WHO, 2014). Menurut Moehji (1988), bayi dengan BBLR cenderung lebih mudah menderita berbagai penyakit infeksi, dan sering mengalami komplikasi yang berakhir dengan kematian yang disebabkan oleh keadaan organ-organ tubuh yang belum sempurna kematangannya.

Menurut WHO anemia adalah suatu kondisi dimana jumlah dan ukuran sel darah merah atau kadar hemoglobin dibawah normal. Kondisi yang tidak normal tersebut menyebabkan berkurangnya asupan oksigen ke jaringan tubuh (WHO, 2014). Faktor risiko anemia dapat berasal dari faktor asupan nutrisi dan non nutrisi. Zat gizi seperti zat besi (Fe), vitamin B12 dan asam folat berperan dalam pembentukan sel darah merah. Apabila tubuh mengalami defisiensi zat gizi tersebut dapat memicu terjadinya anemia. Selain itu faktor non nutrisi yang memicu terjadinya anemia adalah kejadian penyakit infeksi seperti malaria dan kelainan seperti hemoglobinopathies (Kraemer, 2007).

Hasil Analisis hubungan menggunakan uji Chi Square tentang hubungan status anemia ibu hamil dengan kejadian BBLR di wilayah kerja UPTD Puskesmas Manggari Kabupaten Kuningan tahun 2019, diperoleh nilai $\mathrm{p}=0,038$ yang berarti bahwa ada hubungan yang signifikan antara status anemia ibu hamil dengan kejadian BBLR. Dari hasil analisis diperoleh nilai $\mathrm{OR}=3,327$ (95\% CI: $1,184-9,351)$, yang artinya bahwa ibu hamil yang mengalami anemia mempunyai risiko 3,327 kali lebih tinggi dari ibu hamil yang tidak anemia untuk melahirkan BBLR.

Hal ini sesuai dengan teori yang menyatakan bahwa anemia dapat mempengaruhi kualitas hidup penderitanya. Seseorang yang mengalami anemia biasanya mengalami kelelahan, lesu, dan penurunan performa kerja. Hal tersebut terkait dengan terganggunya asupan oksigen dalam tubuh karena kurangnya hemoglobin. Menurut WHO anemia adalah suatu kondisi dimana jumlah dan ukuran sel darah merah atau kadar hemoglobin dibawah normal. Kondisi yang tidak normal tersebut menyebabkan berkurangnya asupan oksigen ke jaringan tubuh (WHO, 2014). Dampak yang ditimbulkan jika terjadi anemia pada masa kehamilan yaitu dikaitkan dengan peningkatan angka mortalitas dan morbiditas pada ibu dan bayi. Selain itu juga dikaitkan dengan risiko terjadinya keguguran, lahir mati, prematur, dan berat badan lahir rendah (WHO, 2014). Menurut (Thomson \& Ward, 2008; PAHO, 2010), anemia yang terjadi pada masa kehamilan berhubungan dengan kejadian BBLR dan peningkatan risiko kematian ibu dan perinatal. Diperkirakan 90.000 kematian ibu dan neonatal disebabkan oleh anemia gizi besi (WHO, 2011). 
Teori ini didukung oleh beberapa hasil penelitian diantaranya yang dilakukan oleh Mohandas Nair, dkk., melalui desain case control dengan sampel sebanyak 200 bayi dari ibu yang berumur 18-35 tahun, di] hasil bahwa ibu dengan kadar $\mathrm{Hb}<$ selama kehamilan memiliki risiko 4,5 kal1 lebih tinggi untuk melahirkan BBLR dibandingkan dengan ibu yang hemoglobinnya $\geq 10 \mathrm{~g} / \mathrm{dl}$. Penelitian lain oleh Rahmati, Shoboo et al berupa tinjauan sistematis literatur dan metode PRISMA dari awal 1990 hingga April 2017 juga menyatakan bahwa secara keseluruhan, dari 17 penelitian dengan ukuran sampel total 245.407 memasuki meta-analisis akhir dan menunjukkan bahwa risiko relatif (RR) untuk anemia ibu pada kehamilan trimester pertama sebesar 1,26 (95\% CI: 1,03-1,55), kedua 0,97 ( 95\% CI: 0,57-1,65), dan ketiga 1,21 (95\% CI: 0,84-1,76), hubungan antara anemia ibu dan BBLR pada trimester pertama kehamilan adalah signifikan.

Bunyarit Sukrat, Chumpon Wilasrusmee, Boonying Siribumrungwong, et al, melakukan tinjauan sistematis dan metaanalisis efek hemoglobin pada hasil kehamilan, diperoleh hasil bahwa dari 17 studi yang termasuk dalam pooling, hemoglobin dibawah $11 \mathrm{~g} / \mathrm{dL}$ masing-masing adalah 1,$10 ; 1,17$; dan 1,14 kali risiko lebih tinggi kelahiran prematur, BBLR, dan bayi kecil untuk usia kehamilan dari hemoglobin normal pada trimester pertama. Pada trimester ketiga, hemoglobin dibawah $11 \mathrm{~g} / \mathrm{dL}$ adalah 1,30 (95\% CI: 1,08-1,58) kali lebih tinggi risiko berat lahir rendah (BBLR).

Berdasarkan hasil penelitian Mutiara Fatinah Endah dengan total sampel 326 bayi baru lahir yang terdiri dari 163 kasus dan 163 kontrol yang memenuhi kriteria inklusi dan eksklusi, diperoleh bahwa anemia pada ibu hamil Trimester III berhubungan dengan kejadian BBLR ( $p=0,017$ OR=1,7). Penelitian ini diperkuat dengan hasil penelitian Pasmawati (2019) menggunakan data Rekam medis RSUD Arga Makmur Bengkulu Utara tahun 2017-2018 dengan jumlah sampel sebanyak 126 kasus dan 126 kontrol. Hasilnya ibu hamil yang anemia pada trimester III, berisiko untuk BBLR 1,70 kali dibandingkan dengan ibu hamil yang kadar Hb-nya normal $(\mathrm{OR}=1,70 \quad(95 \%$ CI: $1,009-2,86))$. Hal ini menunjukkan bahwa ibu hamil diharapkan dapat mempertahankan kadar $\mathrm{Hb} \geq 11,0 \mathrm{gr} / \mathrm{dl}$ melalui konsumsi makanan sumber zat besi atau suplementasi tablet tambah darah (Fe) untuk mencegah terjadinya kasus BBLR.

\section{F. KESIMPULAN DAN SARAN}

1. Kesimpulan

a. Adanya hubungan yang signifikan antara status anemia ibu hamil dengan kejadian BBLR

b. Ibu hamil yang mengalami anemia mempunyai risiko sebesar 3,327 kali lebih tinggi dari ibu hamil yang tidak anemia untuk melahirkan BBLR.

\section{Saran}

Dari hasil penelitian ini, peneliti menyarankan:

1. Bagi ibu hamil, supaya selama kehamilan, dapat mempertahankan kadar $\mathrm{Hb} \geq 11,0$ gr/dl melalui konsumsi makanan sumber zat besi atau suplementasi tablet tambah darah $(\mathrm{Fe})$.

2. Bagi tenaga kesehatan, supaya lebih meningkatkan kembali kegiatan penyuluhan tentang anemia dan pengawasan minum tablet tambah darah (tablet $\mathrm{Fe}$ ) bagi ibu hamil untuk mencegah terjadinya kasus BBLR.

\section{G. DAFTAR PUSTAKA}

Dinkes Kabupaten Kuningan. 2018. Profil Dinas Kesehatan Kabupaten Kuningan. Kuningan

Dinkes Provinsi JABAR. 2016. Profil Dinas Kesehatan Provinsi Jawa Barat. Provinsi Jawa Barat

Kemenkes RI. 2014. Kumpulan Istilah dan Singkatan dalam Bidang Kesehatan. Jakarta: PUSDATIN.

Kemenkes RI. 2018. Hasil Utama Riskesdas 2018. Jakarta: Badan Penelitian dan Pengembangan Kesehatan. 
Lameshow, S et.al, 1990, Adequacy of Sample Size in Health Studies. John Wiley \& Sons. WHO: xii $+239 \mathrm{hlm}$.

Manuaba, dkk. 2010. Ilmu kebidanan, Penyakit Kandungan dan Keluarga Berencana untuk Pendidikan Bidan, Edisi2. Jakarta: EGC

Maryanti, Dwi, dkk. 2011. Penatalaksanaan pada Bayi Risiko Tinggi. Jakarta: Rineka Cipta.

Moehji, S., 1988. Pemeliharaan Gizi Bayi dan Balita. In: Jakarta: Bhatara Karya Aksara.

Mohandas Nair, et al. 2016. Association Between Maternal Anaemia And Pregnancy Outcomes: a Cohort Study in Assam, India. India:BMJ Global Health hal:1-7

Notoatmodjo, Soekidjo. 2010. Metodologi Penelitian Kesehatan. Jakarta: PT. Rineka Cipta.

Prawirohardjo, S. 2010. Ilmu Kebidanan. Jakarta: PT. Bina Pustaka Sarwono Prawirohardjo.

Saifuddin, Abdul Bari. 2008. Ilmu Kebidanan Sarwono Prawirohardjo Edisi Keempat.
Jakarta: PT Bina Pustaka Sarwono Prawirohardjo.

The World Bank. Prevalence of anemia among pregnant women (\%). https://data.worldbank.org/indicator/SH.P RG.ANEM. Diakses pada tanggal 11 Maret 2019

Thomson, Lilian U., dan Ward, Wendy E. 2008. Optimizing women's health through nutrition. USA: CRC Press, Taylor \& Francis Group, LCC

PAHO. 2010. Anemia Among Adolescent and Young Adults Women in Latin America and the Caribbean: A Cause for Concern. World Health Organization.

Pasmawati. 2019. Tesis: Pengaruh Anemia Ibu Hamil Terhadap Berat Badan Lahir Rendah (BBLR) di RSUD Arga Makmur Bengkulu Utara Tahun 2017-2018. Depok:FKM UI

WHO. 2011. Prevention of Iron Deficiency Anaemia in Adolescents: Role of Weekly Iron and Folic Supplementation. New Delhi: South East Asia Regional Office.

WHO. 2014. WHO Global Nutrition Target 2025: Anaemia Policy Brief. 